Provided for non-commercial research and education use. Not for reproduction, distribution or commercial use.

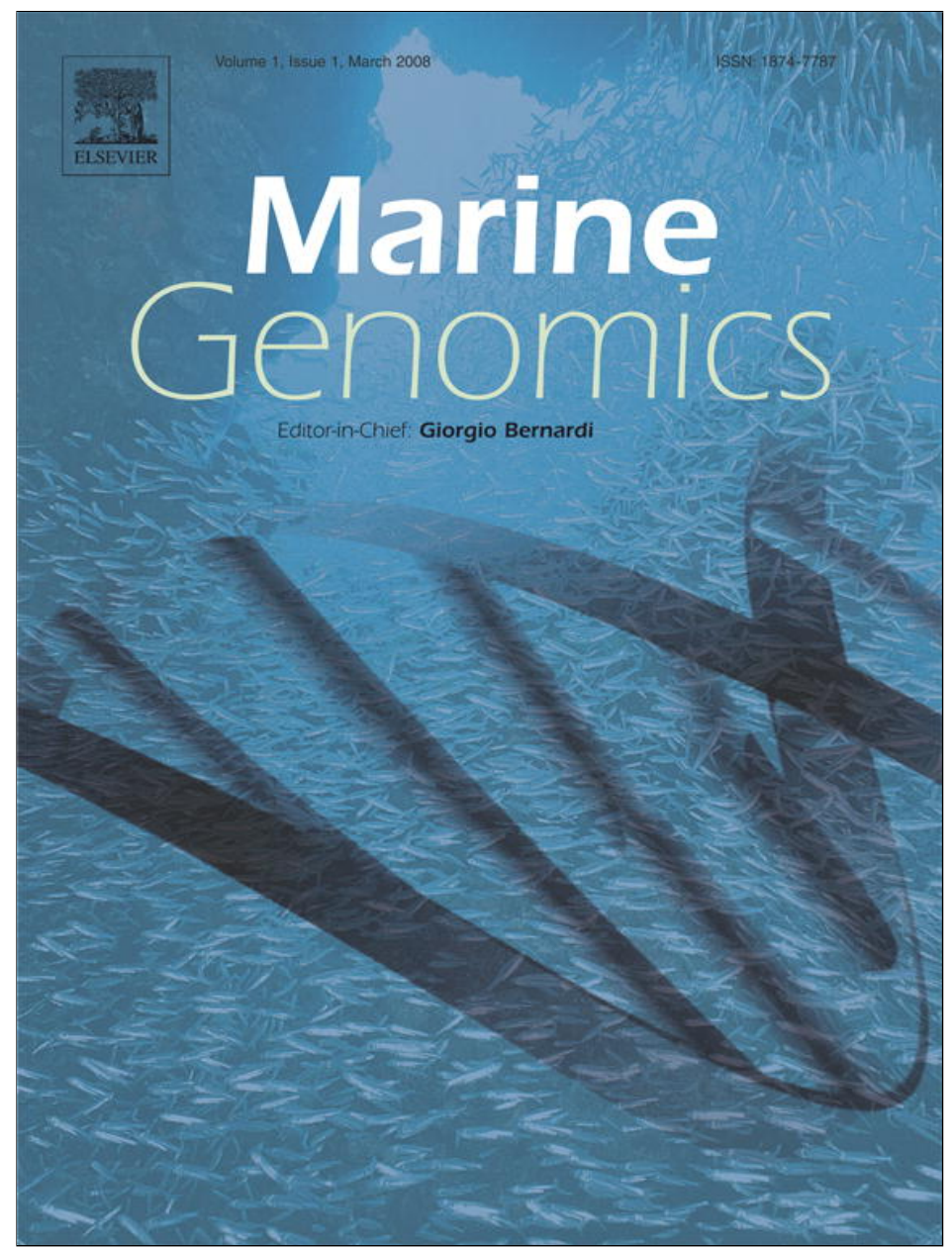

This article appeared in a journal published by Elsevier. The attached copy is furnished to the author for internal non-commercial research and education use, including for instruction at the authors institution and sharing with colleagues.

Other uses, including reproduction and distribution, or selling or licensing copies, or posting to personal, institutional or third party websites are prohibited.

In most cases authors are permitted to post their version of the article (e.g. in Word or Tex form) to their personal website or institutional repository. Authors requiring further information regarding Elsevier's archiving and manuscript policies are encouraged to visit:

http://www.elsevier.com/copyright 
Short communication

\title{
Empowering marine science through genomics is
}

\author{
Filip A.M.J. Volckaert ${ }^{\mathrm{a}, *}$, Michèle Barbier ${ }^{\mathrm{b}}$, Adelino V.M. Canário ${ }^{\mathrm{c}}$, Jeanine L. Olsen ${ }^{\mathrm{d}}$, Johanna Wesnigk ${ }^{\mathrm{e}}$, \\ Melody Clark ${ }^{\mathrm{f}}$, Catherine Boyen ${ }^{\mathrm{b}}$ \\ a Laboratory of Animal Diversity and Systematics, Katholieke Universiteit Leuven, Ch. Deberiotstraat 32, B-3000 Leuven, Belgium \\ b Station Biologique, Place Georges Teissier, BP74, F-29682 Roscoff Cedex, France \\ c Centre of Marine Sciences, University of Algarve, Campus de Gambelas, P-8005-139 Faro, Portugal \\ d Biological Center, Department of Marine Benthic Ecology and Evolution, Centre for Ecological and Evolutionary Studies, \\ University Groningen, P.O. Box 14, NL-9750 AA Haren, The Netherlands \\ e EMPA, Westerdeich 11, D-28197 Bremen, Germany \\ ${ }^{\mathrm{f}}$ British Antarctic Survey, High Cross Madingley Road, Cambridge CB3 OET, UK
}

\section{A R T I C L E I N F O}

\section{Article history:}

Received 29 February 2008

Accepted 1 April 2008

\section{Keywords:}

Blue biotechnology

Future

Marine

Metagenomics

Ocean

Opinion

\section{A B S T R A C T}

Marine scientists in Europe summarize their successes with genome technologies in the marine sciences and make a plea for a concerted international effort to raise greater public education for support.

(c) 2008 Elsevier B.V. All rights reserved.

\section{Introduction}

Oceans are the "cradle of life" containing 95\% of the world's biomass and 38 (19 endemic) of the 39 known animal phyla. They contribute fundamentally to the planet's functioning, yielding some $60 \%$ of the total economic value of the biosphere and, therefore comprise the largest untapped resource on Earth. At the present time, major advances are being made in oceanographic sciences. It is now technically possible to carry out remote and unmanned long-term monitoring of physical and biological processes across ocean basins with data updated in realtime. Allied to this, high through-put genomics techniques have developed a maturity such that tools now exist to enable the monitoring of the links between (microbial) biodiversity and ecosystem function. It is possible to determine how life and ecosystems evolved and how the two function interactively. Therefore linking the latest developments in oceanographic hardware and genomics laboratory-based techniques

\footnotetext{
Funding: This work was supported by the European Commission contract GOCECT-2004-505403.

* Corresponding author. Laboratory of Animal Diversity and Systematics, Katholieke Universiteit Leuven, Ch. Deberiotstraat 32, B-3000 Leuven, Belgium. Tel.: +32 163239 66; fax: +32 16324575 .

E-mail address: filip.volckaert@bio.kuleuven.be (F.A.M.J. Volckaert).
}

provides opportunities for comprehensively understanding global marine biodiversity and ecosystem function at a time when both are severely threatened (Worm et al., 2006). This is indeed an exciting time for marine scientists.

Given the professional excitement and veritable explosion of new marine genomics data, it is disconcerting to learn that still only $10 \%$ of publications are on marine-biodiversity-related studies. Less than $0.1 \%$ of the genomics-related papers (SCI 2002-2007) are devoted to the marine domain as compared with terrestrial/medical studies. We believe that this discrepancy (and it is not new) is fundamentally driven by insufficient public awareness and education. Marine ecosystems are far more important than that portrayed by popular TV images of coral reefs, sharks and extremophiles. It is also a mistaken popular notion that genomics is commercially restricted to human health, agriculture and nanotechnology.

Genomics provides the tools to unravel key issues and processes related to climate change, loss of biodiversity and ecosystem function. We can reconstruct the Tree of Life, understand the evolution of genomes and the myriad of ways in which gene networks affect adaptive evolution. These are the more tractable challenges now awaiting today's marine genomic scientists. Unfortunately, these topics are also more abstract and difficult for the public to appreciate despite their fundamental societal relevance. This state of affairs keeps 
them in the background and ultimately at the end of the funding queue. In this essay, we highlight some of the early genomics-driven advances in marine sciences, evaluate the state-of-play, and offer some thoughts on how to bring the public onboard in order to better balance resource allocation and facilitate integration of the marine genomics community with our terrestrial colleagues.

\section{Major discoveries: sequence exploitation}

The number of sequenced eukaryotic marine genomes in phylogenetically or ecologically interesting species is still tiny (83 taxa of which 8 are marine; www.genomesonline.org). However this is steadily increasing, e.g., the recent publication of the sea urchin genome (Sodergren et al., 2006). Because almost half of the recognized phylogenetic lineages of eukaryotes are endemic to the oceans, their inclusion in the Tree of Life - and eventually, the Network of Life - is absolutely essential as we begin to understand convergent and emergent developmental properties of protists, metazoans and fungi. Each new sequence reveals something amazing, like the discovery of a complete urea cycle in the diatoms, a chimeric leftover from an ancient heterotrophic host before it captured a red alga to become its plastid; or the switch from uni- to multicellularity and a new take on the evolution of the vertebrates (Delsuc et al., 2006). At the "unseen" microbial level, the diversity is overwhelming (Pedrós-Alió, 2007). The number of sequenced marine prokaryote genomes currently stands at more than hundred (http://www.moore. org/microgenome) and is increasing every day. In parallel, metagenomic approaches are identifying community-specific patterns in gene distribution, from bacteriophage populations in the Arctic, through acid mine drainage water assemblages through to ocean microbial communities off Nova Scotia. Again, the discoveries are many, e.g., rhodopsin-based photosynthetic within a sizeable portion of this community (Beja et al., 2001), new biochemical pathways, and hydrocarbon degrading bacteria (Schneiker et al., 2006).

\section{Blue food, medicine and biotech}

Overfishing is the number-one-threat to marine biodiversity, yet wild ocean fisheries still account for $70 \%$ of human fish consumption. Marine fishes have declined in breeding biomass by $65 \%$ from known historic levels (Reynolds et al., 2005) and some $29 \%$ of all commercial fish stocks have collapsed. The result is a decrease of the average food chain length, which reduces ecosystem stability and could lead to an irreversible cascade to a new trophic dynamic (Worm et al., 2006). In addition, the loss of potential to adapt to new environmental conditions under global warming is about one order of magnitude faster than the estimated recovery (Drinkwater, 2005). Thus, a crucial test for the value of genomics will be to fully understand the impact of fishing on marine populations and food web structure. At present, five fish genomes have been sequenced, but these are very much "model organisms", chosen for their biomedical potential and are not representative marine fish. Given the extensive "classical" biological literature on fish, including a nearly complete species inventory (www.fishbase.org), opportunities for genome comparisons remain wide open, thus providing a good balance between opportunities for intellectual contributions in tandem with global environmental issues.

Many human pathogens (e.g., Legionella and Vibrio) and parasites (e.g., the helminths Cryptocotyle sp. and Anisakis simplex) are intimately linked to the ocean environment but difficult to track. This is also true for the production of toxins by harmful algal blooms. Subsequent human consumption of contaminated shellfish and fish that have fed on the algae are increasingly widespread but still poorly understood. New ecogenomic technologies in the form of chip detection (some mounted on underwater observatories) will be able to identify and follow these microbes, thus providing the tools for early detection and prediction of outbreaks, especially if combined with physical models. Development of marine models for human medicine and physiology (e.g., cell cycle regulation in cancer research based on echinoderm models) are still in the nascent stage but seem promising. Biotech has already benefited from the discovery of 12,000 new natural products, some of them representing exotic chemicals, from all marine organisms imaginable over the past 20 years. Alternative biochemical pathways have been elucidated that could not have succeeded without genomic information (Glöckner et al., 2003).

\section{Obstacles}

At present, the politics of "what gets sequenced" is driven to a large extent by biomedical interests and the implications for human health. The current trend of some large sequencing centres to shift greater than $50 \%$ their resources toward human re-sequencing projects, further impedes access to such facilities for marine scientists. As a general rule, environmental funding has lagged behind, partly because understanding function and processes as they occur in nature, up until recently, has not been a tractable issue. Complex natural communities comprising hundreds/thousands of species, many of them, submicroscopic, do not conform to the classical definitions of model organisms. However, it is precisely the newly isolated "bug" isolated par hazard in a metagenomics library that often holds a key position in ecosystem function. Marine scientists need to be able to re-define environmental models or concepts that are the actual players in the environment; and not distant proxies. They also need to make these media-worthy and excite public interest in them.

Genome sequencing costs are rapidly becoming cheaper, but major genome projects are still expensive. This has a serious delaying effect on progress, especially with respect to the larger eukaryotic genomes. Shortcuts in the form of reduced coverage and or partial sequencing will help to enhance the diversity of genomes that can be sequenced now (e.g., dinoflagellates). These will also provide the data for comparative methods, which are essential to long-range science development. While there is no doubt that high profile large-scale sequencing of marine systems like the Sargasso Sea project (Venter et al., 2004) have pushed marine sciences into the new millennium, it is now time to convert information into knowledge. Data dredging and discovery have to be followed by hypothesis-driven research. For example, extensive integration of contextual habitat information with organism and (meta)genomic data (www.metafunctions.org) is the key to understanding the global cycling of nutrients and energy. Marine scientists are rapidly becoming conversant with genomics techniques and are ideally placed to a) identify worthwhile and exploitive environmental genomics projects, b) provide essential support and contextual information for genomics exploitation via interdisciplinary teams, for example combining scientists from oceanography, fisheries, physiology, ecology etc., c) re-visit "old problems", which are still current, such as algal blooms, fisheries population structure, mate selection, homing in salmon etc., with new techniques.

This type of research follows the general trend of genomics shifting biological research from the single-investigator to a multi-disciplinary approach, where many specialists work together in teams. This is still difficult for the marine research community. Historical fragmentation means that many marine research groups are in single departments scattered throughout universities or in satellite marine laboratories. Things are changing with major bootstrapping efforts in combination with various initiatives of the European Commission. Progress is being made to assemble a European-wide critical mass. The EU Framework Programme 6 Network of Excellence, Marine Genomics Europe (www. marine-genomics-europe.org) bundles virtually all of the research community involving some 45 laboratories, 118 teams and $>600$ researchers. Combined with her sister networks, Marine Biodiversity and Ecosystem Function (www.marbef.org) and EurOceans (www. 
eur-oceans.org), the total is more than 2000 researchers. Still, a scientific-community-added-value can only be delivered with full support by national funding agencies, which support individual investigators within this larger whole.

\section{The future for marine genomics}

We need to understand how our blue planet functions. To reach this lofty goal will require an intimate understanding of the linkages between the ocean-atmospheric interface at the physical-chemical level and the linkages between the organism-environmental interface at the biological level. Genomic sciences provide these linkages.

Tapping public enthusiasm will require education because of lack of familiarity with most marine life and the many abstract concepts. Forty years ago, the public learned some basic physics about "outerspace": the vacuum of space, escape velocity and gravity which produced an armchair enthusiasm for space exploration that critics had not predicted. Today's challenge for marine scientists is perhaps conceptually more subtle but we have the enhanced media tools of 24 hour broadcasting and educational television programmes with up-to-the-minute findings based on live links. TV programmes are increasingly linked to educational web sites and provide ideas for sophisticated computer games. Given that the 21 st century has been proclaimed the century of biology, we believe that with the correct marketing of marine (genomic) sciences within the larger context of ocean science can have the effect that Jacques Cousteau's Underwater World had on the public 50 years ago.

\section{References}

Beja, O., Spudich, E.N., Spudich, J.L., et al., 2001. Proteorhodopsin phototrophy in the ocean. Nature 411, 786-789.

Delsuc, F., Brinkmann, H., Chourrout, D., et al., 2006. Tunicates and not cephalochordates are the closest living relatives of vertebrates. Nature 439, 965-968.

Drinkwater, K.F., 2005. The response of Atlantic cod (Gadus morhua) to future climate change. ICES J Mar Sci 62, 1327-1337.

Glöckner, F.O., Kube, M., Bauer, M., et al., 2003. Complete genome sequence of the marine planctomycete Pirellula sp strain 1. Proc. Natl. Acad. Sci. U. S. A. 100, 8298-8303.

Pedrós-Alió, C., 2007. Dipping into the rare biosphere. Science 315, 192-193.

Reynolds, J.D., Dulvy, N.K., Goodwin, N.B., et al., 2005. Biology of extinction risk in marine fishes. Proc. Royal Soc. B Biol. Sci. 272, 2337-2344.

Schneiker, S., dos Santos, V.A.P.M., Bartels, D., et al., 2006. Genome sequence of the ubiquitous hydrocarbon-degrading marine bacterium Alcanivorax borkumensis. Nat. Biotechnol. 24, 997-1004.

Sodergren, E., Weinstock, G.M., Davidson, E.H., et al., 2006. The genome of the sea urchin Strongylocentrotus purpuratus. Science 314, 941-952.

Venter, J.C., Remington, K., Heidelberg, J.F., et al., 2004. Environmental genome shotgun sequencing of the Sargasso Sea. Science 304, 66-74.

Worm, W., Barbier, E.B., Beaumont, N., et al., 2006. Impacts of biodiversity loss on ocean ecosystem services. Science 314, 787-790. 